\title{
Teorias Críticas Latino-Americanas: leitores e leituras decoloniais de Foucault ${ }^{1}$
}

\author{
Clayton Roberto Messias ${ }^{2}$
}

Carlos Roberto da Silveira ${ }^{3}$

\begin{abstract}
Resumo
Neste artigo analisa-se, na perspectiva das Teorias Críticas Latino-Americanas (TCLA's), ideias de Michel Foucault acerca do saber colonial desde suas primeiras formulações. Para tanto, são utilizadas considerações de Aníbal Quijano, Catherine Walsh, Enrique Dussel, Santiago Castro-Gómez, Ramón Grosfoguel, Walter Mignolo, entre outros, assim como, citações do curso Em defesa da sociedade (1975-1976) de Foucault, para aprofundamentos da temática Decolonialidade do Saber. Este artigo recebeu contribuições do Grupo de Pesquisa Sobre Educação e Teorias Críticas Latino-Americanas (GPETCLA) e do Grupo de Pesquisa Estudos Foucaultianos e Educação (GPEFE) do Programa de Pós-graduação Stricto Sensu em Educação da Universidade São Francisco (USF).

Palavras-chave: Saber colonial; Teorias Críticas Latino-Americanas; Decolonialidade do saber.
\end{abstract}

\section{Education and Latin American Critical Theories: readers and decolonial readings of Foucault}

\section{Abstract}

In this article we analyze, from the perspective of Critical Latin American Theories (TCLA's), ideas of Michel Foucault on colonial knowledge since its earliest formulations. Therefore, considerations by Aníbal Quijano, Catherine Walsh, Enrique Dussel, Santiago Castro-Gómez, Ramón Grosfoguel, Walter Mignolo, among others, as well as quotations from the course In defense of society (1975-1976) by Foucault, to deepen the theme of Decoloniality of Knowledge. This article received contributions from the Research Group on Education and Critical Theories of Latin America (GPETCLA) and the Foucauldian Studies and Education Research Group (GPEFE) of the Post-graduation Stricto Sensu in Education of the University San Francisco (USF).

Keywords: Know colonial; Latin American Critical Theories; Education and decoloniality of knowledge.

\section{Considerações iniciais}

Neste artigo pretende-se apresentar o "Projeto Modernidade/Colonialidade" fundamentado pelos Estudos Decoloniais ${ }^{4}$ e realizar uma análise introdutória sobre certas ideias de alguns integrantes do "Grupo Modernidade/Colonialidade (M/C)" que contribuíram e contribuem para o desenvolvimento das Teorias Críticas Latino-Americanas (TCLA's).

Entre os estudiosos que se encontram nesta linha de pesquisa estão Aníbal Quijano, Catherine Walsh, Enrique Dussel, Ramón Grosfoguel, Santiago Castro-Gómez e Walter Mignolo,

\footnotetext{
${ }^{1}$ Esse trabalho é fruto de uma Dissertação de Mestrado.

2 Senac e Etec, Jundiaí, clayton_messias@hotmail.com

${ }^{3}$ Universidade São Francisco (USF), Itatiba, carlos.silveira@usf.edu.br

${ }^{4}$ A categoria "decolonialidade" foi desenvolvida pelo filósofo porto-riquenho Nelson Maldonado-Torres em 2006 e complementa a categoria "descolonização", utilizada pelas Ciências Sociais no final do século XX.
}

Periódico Horizontes - USF - Itatiba, SP - Brasil - e019030 
entre outros. As ideias originadas por esses estudiosos têm influenciado os processos de Educação e Decolonialidade do Saber, na perspectiva das TCLA's.

Entre outras razões, analisa-se que os chamados processos de colonialidade permitiram a geração de um constante debate acadêmico sobre a validade da produção de conhecimento não eurocêntrico, em particular na América Latina. Logo, constituiu-se o chamado "Projeto Modernidade/Colonialidade", dedicado aos Estudos Decoloniais.

Portanto, devido à proposta deste artigo e à complexidade da temática, realiza-se uma análise introdutória sobre as ideias desenvolvidas no Projeto Modernidade/Colonialidade e se referenciam alguns estudiosos dos processos de Decolonialidade do Saber, sobretudo para fundamentar uma "Teoria Crítica" que permita promover Epistemologias Latino-Americanas, além da que se denomina Saber Eurocêntrico.

Demonstra-se, ainda, as contribuições de uma investigação epistêmica regulada na articulação entre as dimensões pedagógica e decolonial ao se pensar que as práticas no campo da Educação podem ser concebidas a partir da perspectiva da Decolonialidade.

Por fim, examina-se um ponto de vista foucaultiano acerca do Saber Colonial e da Decolonialidade do Saber desde suas primeiras inserções até seu encontro com as TCLA's para justificar o tema "Educação e Decolonialidade do Saber".

A respeito da "Transmodernidade", Enrique Dussel declara que a problemática aludida sobre a "Pós-modernidade" pelos europeus nos anos 1980 era diferente do que se chamava de pós-moderno nas teorias críticas Latino-Americanas. Compreendia também o fenômeno da "Modernidade" de forma distinta, pois era vista a partir da América Latina, isso desde o (des)encontro, do (en)cobrimento do outro (o Ameríndio) e do nascimento da periferia colonial cujo centro tornou-se a Europa.

Para Dussel, o conceito de Modernidade é visto, ainda, a partir da Europa e Estados Unidos com conotação eurocêntrica, conforme afirmado por Lyotard, Vattimo, Habermas e Wallerstein, entre outros. Porém, diferentemente, para os latinoamericanos, a Modernidade nasceu com a invasão da América pelos espanhóis (1492), momento em que a constituiu como propriedade, como colônia com escravos no surgimento de um novo pagão.

Silveira e Agostini (2017, p.543), no texto A bíos no discurso do logos: pessoa/participante hígida em projetos de pesquisa em saúde no Brasil, enunciam que:

Periódico Horizontes - USF - Itatiba, SP - Brasil - e019030 
Para as nossas bandas, o (des)encontro foi inevitável entre os europeus e os ameríndios. Anterior à data de 12 de outubro de 1492, de acordo com o pensamento de Dussel (1980, p.14), a Europa germano-latina não existia senão como periferia, pois estava encurralada pelo mundo árabe-turco que se estendia desde o Sul da Espanha, em Andaluzia, até as portas de Viena logo depois da queda de Constantinopla.

Assim, "Transmodernidade", ao contrário da Pós-modernidade, pretende uma novidade radical que parte da exterioridade desprezada, da alteridade negada, das culturas subalternizadas, do diálogo intercultural e multicultural, das diferenças, do atravessamento da cultura do centro, da liberdade humana. Segundo Dussel (2012, p.49), “a Transmodernidade indica os aspectos que se situam antes e depois das estruturas valoradas pela Modernidade Europeia e Norte-Americana, vigentes nas grandes culturas universais não-europeias".

\section{Fundamentações decoloniais: projeto Modernidade/Colonialidade}

Com o propósito de apresentar um panorama dos eixos fundamentais que constituem essa investigação, foi iniciado um estudo analítico sobre as ideias de integrantes do Grupo Modernidade/Colonialidade $(\mathrm{M} / \mathrm{C})^{5}$, com a contribuição de Santiago Castro-Gómez cuja tese indicou a necessidade de decolonialidade, ou seja, da realização do processo de desconstrução das epistemes da colonialidade do saber, do poder e do ser. Castro-Gómez é um dos teóricos que desenvolveu a problemática da colonialidade e, desde suas investigações, defendeu que:

A visão colonial sobre o mundo obedece um modelo epistêmico implantado pela Modernidade ocidental, [...] tanto no pensamento como nas estruturas, a Universidade se inscreve na chamada estrutura triangular da colonialidade: a colonialidade do saber, a colonialidade do poder e a colonialidade do ser (CASTRO-GÓMEZ, 2007, p.79-80).

Outro participante do Grupo M/C, o sociólogo Aníbal Quijano, esteve durante anos como colaborador ativo desse grupo de pensadores latino-americanos. Entretanto, antes da

\footnotetext{
${ }^{5} \mathrm{O}$ Grupo Modernidade/Colonialidade (M/C) é um dos mais importantes coletivos do pensamento crítico criado na América Latina no final do século XX. Trata-se de uma rede multidisciplinar de intelectuais entre os quais se contam Aníbal Quijano, Catherine Walsh, Edgardo Lander, Enrique Dussel, Ramón Grosfoguel, Santiago Castro-Gómez e Walter Mignolo, entre outros, que postularam e postulam as Teorias Críticas Latino-Americanas.
}

Periódico Horizontes - USF - Itatiba, SP - Brasil - e019030 
fundamentação, sobretudo da colonialidade do saber, cabe aqui um breve exame histórico a respeito do "Projeto Modernidade/Colonialidade".

Em 1998, com o apoio do Conselho Latino-Americano de Ciências Sociais (CLACSO), Edgardo Lander organizou o Congresso Mundial de Sociologia no Simpósio Alternativas ao Eurocentrismo e ao Colonialismo no Pensamento Social Latino-Americano Contemporâneo, no qual participaram, entre outros, Aníbal Quijano, Enrique Dussel e Walter Mignolo.

Desse evento surgiu um dos mais significativos livros já produzidos pelo Grupo M/C: $A$ Colonialidade do Saber: eurocentrismo e ciências sociais, perspectivas latino-americanas ${ }^{6}$, organizado por Lander e publicado, em português, pela CLACSO em 2005.

No ano de 1999, o Grupo M/C organizou um outro evento onde se iniciou o diálogo com as Teorias Pós-Coloniais da Ásia, África e América Latina. Aníbal Quijano, Edgardo Lander e Walter Mignolo participaram do Simpósio Internacional La reestructuración de las ciencias sociales en los países andinos, organizado por Castro-Gomez, em agosto de 1999, em Bogotá.

Desse evento resultaram dois livros que, junto com o de Lander, constituiriam as primeiras publicações do grupo: Pensar (en) los interstícios: teoría y práctica de la crítica poscolonial (1999) $)^{7}$ e La reestructuración de las ciências sociales en América Latina (2000) ${ }^{8}$, ambos editados pelo Instituto de Estudos Sociais e Culturais Pensar.

Foi a partir desse evento que se firmou um convênio de cooperação acadêmica entre a Universidad Javeriana, a Duke University, a University of North Caroline e a Universidad Andina Simón Bolívar para organizarem atividades e publicações em torno do tema Geopolíticas do Conhecimento e a Colonialidade do Poder.

Foi em eventos como esses que Dussel, Mignolo e Quijano se reuniram para discutir sobre as heranças coloniais na América Latina em diálogo com as pesquisas do norte americano Immanuel Wallerstein, diretor do Centro Ferdinand Braudel em Paris e fundador de um dos enfoques mais inovadores da sociologia ocidental: a análise do sistema-mundo.

Para Quijano e Wallerstein (1992, p.583):

\footnotetext{
${ }^{6}$ LANDER, E. (Org.). A colonialidade do saber: eurocentrismo e ciências sociais, perspectivas latino-americanas. Trad. Conselho Latino-Americano de Ciências Sociais (CLACSO). São Paulo: CLACSO, 2005.

${ }^{7}$ CASTRO-GÓMEZ, S.; RIVERA, O. G.; BENAVIDES, C. M. (Org.). Pensar (en) los interstícios: teoría y práctica de la crítica poscolonial. Bogotá: Instituto Pensar, 1999.

${ }^{8}$ CASTRO-GÓMEZ, S. La reestructuración de las Ciências Sociales en América Latina. Bogotá: Instituto Pensar, 2000.
} 
O moderno sistema-mundo nasceu ao longo do século XVI. A América, como entidade geosocial, nasceu ao longo do século XVI. A criação desta entidade geosocial, América, foi um ato constitutivo do moderno sistema-mundo. A América não se incorporou em uma já existente economia-mundo capitalista. Uma economia-mundo capitalista não teria acontecido sem a América.

Por sua vez, Dussel era reconhecido na América Latina por ser um dos fundadores da "Filosofia da Libertação" nos anos 70, enquanto Mignolo começava a ser reconhecido no crescente círculo dos estudos pós-coloniais.

A abordagem entre a análise do Sistema-Mundo e as Teorias Críticas Latino-Americanas sobre a Colonialidade continuou em 2000, quando Ramón Grosfoguel organizou, em Boston, uma conferência convidando o filósofo colombiano Santiago Castro-Gómez.

Em 2001, a primeira reunião do Grupo M/C foi organizada por Walter Mignolo na Duke University sob o nome de Knowledge and the Known. Nesse evento se uniu ao Grupo M/C a Professora da Universidad Andina Simón Bolívar Catherine Walsh, que ficou encarregada de organizar a segunda reunião do Grupo M/C no ano 2002 na cidade de Quito, Equador.

Na segunda reunião do Grupo M/C, foi produzido o livro Indisciplinar las ciencias sociales: geopolíticas del conocimiento y colonialidad del poder ${ }^{9}$, editado por Catherine Walsh e Santiago Castro-Gómez e publicado pela editora Abya-Yala de Quito, Equador, em 2002.

A terceira reunião do Grupo M/C foi organizada em 2003, por Ramón Grosfoguel e aconteceu na Berkeley University, Califórnia.

A quarta reunião aconteceu em abril de 2004 na Universidade da Califórnia, após a qual se publicou o livro intitulado Latin@s in the World-System: Decolonization Struggles in the 21st Century U.S. Empire ${ }^{10}$, editado por Grosfoguel, Maldonado-Torres e publicado em 2005.

Essa conferência, organizada por Grosfoguel, teve como tema principal A descolonização do império norte-americano no século XXI. Nessa ocasião, o Grupo M/C iniciou um diálogo com o Sociólogo português Boaventura de Sousa Santos, um dos organizadores e teóricos do Fórum Social Mundial (FSM).

A quinta reunião foi organizada em junho de 2004 por Mignolo na Universidade da

\footnotetext{
9 WALSH, C.; CASTRO-GÓMEZ, S. (Org.). Indisciplinar las ciencias sociales: geopolíticas del conocimiento y colonialidad del poder, perspectivas desde lo andino. Quito, Ecuador: Ediciones Abya-Yala, 2002.

${ }^{10}$ GROSFOGUEL, R.; MALDONADO-TORRES, N.; SALDÍVAR, J. D. (Orgs.). Latin@s in the World-System: Decolonization Struggles in the 21st Century U.S. Empire. Boulder, Colorado: Paradigm Publishers, 2005.
}

Periódico Horizontes - USF - Itatiba, SP - Brasil - e019030 
Carolina do Norte e na Duke University com o título de Teoría Crítica y Decolonialidad e ,no último Fórum Mundial de Caracas, o Grupo M/C coordenou três painéis sob o título: Decolonialidad del Saber: saberes otros, revoluciones otras.

Entre as produções do Grupo $M / C$, para este artigo científico, destacam-se obras Colonialidade do Poder, Eurocentrismo e América Latina, de Quijano e 1492 O Encobrimento do Outro: a origem do mito da Modernidade ${ }^{11}$, de Enrique Dussel.

Sendo assim, o "Projeto Modernidade/Colonialidade" estaria em argumentação com a ideia europeia de qualificar as periferias como sociedades pré-modernas ou subdesenvolvidas. Entretanto, as elites crioulas latino-americanas, de descendência europeia, mantém a mesma lógica discursiva para reivindicar sua superioridade sobre os demais, sobre "os Outros".

Castro-Gómez e Grosfoguel também compartilharam a crítica que Leopoldo Zea, em seu livro América Latina en Sus Ideas, chamou de "nordomanía", isto é, "o esforço das elites crioulas dos países periféricos por imitar os modelos de desenvolvimento provenientes do norte, que implica uma reprodução de antigas formas de colonialismo.

"Nordomanía" foi o termo introduzido pelo ensaísta uruguaio José Enrique Rodó para descrever quem, no choque cultural entre o Norte e o Sul da América, optou por subordinar-se aos valores anglo-saxões predominantes nos Estados Unidos da América do Norte.

Zea (1986, p.17) enunciou que entre 1492 e 1824, entre o início do Encobrimento da América e a Batalha de Ayacucho, "se enfrentou o primeiro encobrimento cultural. A primeira consciência da dependência sofrida foi tomando corpo até provocar a explosão que colocaria em situação de crise este primeiro encobrimento".

Entende-se, portanto, que o encobrimento cultural e a consciência da "nordomanía" fizeram surgir o afã por definir-se o próprio gesto de libertação da cultura do opressor, ou seja, o processo pelo qual os povos do Sul não se ajustam ao sistema estadunidense.

A “nordomanía” é, portanto, um processo que concorda em afirmar a existência de uma Colonialidade que impede a diversidade de epistemes e pedagogias no interior de uma sociedade, um processo que permite concluir que a descolonização ainda não está acabada. Logo, para Castro-Gomez e Grosfoguel (2007, p.13), "assistimos a uma transição do colonialismo

\footnotetext{
${ }^{11}$ DUSSEL, Enrique. 1492 o encobrimento do outro: a origem do mito da modernidade. Trad. Jaime A. Clasen. Petropolis, RJ: Vozes, 1993.
}

Periódico Horizontes - USF - Itatiba, SP - Brasil - e019030 
moderno à colonialidade, processo de transformação das formas de dominação implantadas pela Modernidade, mas não da estrutura centro-periférica em escala mundial".

Em conclusão, as linhas investigativas do Projeto Modernidade/Colonialidade caracterizam-se por sua leitura Decolonial das ações que redefinem a consciência eurocêntrica, portanto, interpelam às epistemologias que questionam os Movimentos Latino-Americanos enquanto atores teórico-críticos da Modernidade.

O Projeto Modernidade/Colonialidade conta com uma quantidade considerável de estudiosos em programas acadêmicos como: o Doutorado em Estudos Culturais da Universidad Andina Simón Bolívar; o Mestrado em Investigação sobre Problemas Sociais Contemporâneos do Instituto de Estudios Sociales Contemporáneos (IESCO) da Universidad Central em Bogotá e o Seminário-Taller "Fábrica de Ideias”, em Salvador, Bahia, Brasil, entre outros.

\section{Saber colonial: uma perspectiva foucaultiana}

Nesta sessão pretende-se analisar como as fundamentações teóricas pós-coloniais constituíram historicamente sua hegemonia nas epistemologias latino-americanas.

Uma das contribuições é a de Castro-Gómez, que se colocou em uma posição periférica em relação aos sinais de identidade dos estudos coloniais na medida em que se aprofundou no desenvolvimento historiográfico das técnicas foucaultianas.

Castro-Gómez (2007, p.156), fundamentou sua tese de que Foucault, nas aulas dos cursos Em defesa da sociedade (1975-1976) e Segurança, território, população (1977-1978), "desenvolveu uma teoria heterárquica como contraponto para mostrar quais problemas incluem as 'teorias hierárquicas', desde que se têm pensado o tema da colonialidade".

Castro-Gómez e Grosfoguel (2007, p.18) classificaram o pensamento heterárquico como "uma tentativa de conceituar estruturas sociais com uma nova linguagem que vai além do paradigma da ciência social eurocêntrica herdada do século XIX".

Logo, esta linguagem eurocêntrica é para regimes extremamente fechados, pelo fato de ter uma lógica que estabelece plenamente os outros sistemas a partir de hierarquias de poder.

Contudo, as heterarquias são estruturas horizontais em que não existe um alto nível que governe os demais, senão que todos exercem algum grau de influência mútua em diferentes

$$
\text { Periódico Horizontes - USF - Itatiba, SP - Brasil - e019030 }
$$


aspectos, atendendo as conjunturas específicas.

Para uma melhor compreensão dos postulados, Castro-Gómez e Grosfoguel analisaram as ideias de Michel Foucault, da aula de 7 de janeiro de 1976, do curso Em defesa da sociedade.

Nesta aula, Foucault discorreu a respeito dos temas: os saberes sujeitados; o saber histórico das lutas, as genealogias e o discurso científico; o poder, o que está em jogo nas genealogias; concepção jurídica e econômica do poder; o poder como repressão e guerra.

Portanto, quando Foucault discorreu sobre a Genealogia do Saber, ou seja, sobre a vinculação das ciências e das memórias locais que possibilitaram o emprego desse saber nas táticas contemporâneas e no estabelecimento de um saber histórico das lutas, percebe-se que a "Teoria Hierárquica do Saber" é evidenciada sob uma perspectiva da Colonialidade do Saber.

De acordo com Foucault (1999, p.13), "trata-se de fazer que intervenham saberes locais, descontínuos, desqualificados, não legitimados, contra a instância teórica unitária que pretende filtrá-los, ordená-los, hierarquizá-los, em nome de um conhecimento verdadeiro, em nome de uma ciência possuída por alguns".

Foucault referiu-se à "insurreição dos saberes sujeitados", não em oposição aos procedimentos de uma ciência, mas à resistência contra os impactos centralizadores do poder que é vinculado ao funcionamento de um enunciado científico estruturado em uma sociedade.

Para Foucault (1999, p.14), pouco importava "se a institucionalização do discurso científico toma[sse] corpo numa universidade, ou num aparelho pedagógico, se toma[sse] corpo numa rede teórico-comercial como a psicanalise, ou num aparelho político [...]", sobretudo, era em oposição às consequências do poder próprios de um discurso científico que a genealogia deveria combater.

Consequentemente, a Genealogia do Saber passaria a ser relacionada ao escopo de uma insurgência dos saberes à hierarquia do poder, seria uma forma de projeto para,

dessujeitar os saberes históricos e torná-los livres, isto é, capazes de oposição contra a coerção do discurso teórico, formal, científico [...] a arqueologia seria o método próprio de análise das discursividades locais, e a genealogia a tática que faz intervir, desde as discursividades descritas, os saberes dessujeitados que daí se desprendem (FOUCAULT, 1999, p.15-16).

Conota-se aqui, acerca da Decolonialidade do Saber, enquanto "saberes dessujeitados".

Periódico Horizontes - USF - Itatiba, SP - Brasil - e019030 
Portanto, ainda não havia chegado o tempo da colonização, como Foucault queria tentar, nos cursos seguintes, delinear o que está[va] em jogo nesse "pôr em insurreição os saberes contra a instituição e os efeitos de saber e poder do discurso científico".

Em 14 de janeiro de 1976, Foucault $(1999$, p.40) afirmou que "no ponto em que terminam as redes de poder, o que se formam, não são ideologias, são instrumentos de acúmulo de saber" e enunciou que uma das suas inquietações era que as "máquinas de poder" fossem assistidas por ideologias como a da Educação.

Entretanto, o poder quando exercido em seus "mecanismos finos", não acontece sem o desenvolvimento do saber, ou seja, sem os métodos de observação, técnicas de registro, procedimentos de investigação e aparelhos de verificação.

Resumindo suas precauções sobre "mecanismos finos", Foucault $(1999$, p.40) disse que:

[...] em vez de orientar a pesquisa sobre o poder para o âmbito das ideologias que o acompanham, deve-se orientar a análise do poder para o âmbito da dominação, dos operadores materiais, das formas de sujeição, das utilizações dos sistemas locais dessa sujeição e para o âmbito dos dispositivos de saber.

Portanto, as disciplinas eram extremamente inovadoras em relação a esses dispositivos de formação de saberes e de epistemes, próprios de um discurso.

Foucault (1999, p.45) defendeu que as "disciplinas" tinham sua própria discursividade e constituíram os "aparelhos de saber, de saberes e de campos múltiplos de conhecimento".

Sobretudo, o método que tornou possível a circulação de enunciados discursivos das Ciências Humanas foi a sobreposição, ou seja, o embate de dois mecanismos e de dois tipos de discursos heterogêneos.

Logo, Foucault (1999, p.46) defendeu que, "de um lado, a organização do direito em torno da soberania, do outro, a mecânica das coerções exercidas pelas disciplinas".

Na aula de 21 de janeiro de 1976, Foucault retomou a problemática a respeito da dialética da colonização e pacificação soberana do discurso que traçava seu caminho por séculos na Europa, ocasionalmente na luta, na guerra.

Foucault (1999, p.71) expôs que essa é "uma teoria que vai se articular com base nos movimentos e na luta das nacionalidades contra os grandes aparelhos de Estado na Europa a 
partir da política da colonização europeia".

Nessa ocasião, surgiria a "teoria das raças", portanto, na aula de 28 de janeiro de 1976 Michel Foucault justificou que não foi do discurso racista que ele quis fazer a história, mas do discurso da "luta das raças". Importa aqui designar a sentença "racismo" ou "discurso racista" a um episódio, específico e restrito, do discurso sobre os mecanismos da "luta das raças". Foi no final do século XIX, o retorno do "racismo" como objetivo discursivo de dominação social.

Essa história da "luta das raças" surgiu nos séculos XVI e XVII como uma contra-história que Foucault (1999, p.85) define como: "aquela da servidão sombria, da degradação, da profecia e da promessa, aquela do saber secreto que deve ser reencontrado e decifrado".

Logo, esses enunciados discursivos do saber e da subversão violenta da ordem das coisas, demonstrados por Foucault, foram sujeitados, não mais a um discurso racista, mas à seguinte subdivisão da sociedade "de um lado uns, do outro os outros, os justos e os injustos, os senhores e aqueles que lhes são submissos, os ricos e os pobres, os poderosos e aqueles que só têm seus braços, os invasores das terras e aqueles que tremem diante deles, os déspotas e o povo ameaçador [...] (FOUCAULT, 1999, p.86).

Retoma-se aqui a análise sobre a Teoria Heterárquica, que seria um projeto constituinte da Colonialidade do Saber, isto é, um projeto capaz de resistência ao discurso teórico formal e científico. Para Castro-Gómez e Grosfoguel (2007, p.17-18), essa é "uma das vertentes da colonialidade", ou seja, o "outro" no projeto de inserção dos saberes na hierarquia do poder.

Sob o ponto de vista historiográfico do Saber Colonial, Foucault $(1999$, p.89) considerou que no século XIX esse discurso, "foi vinculado ao projeto de escrever uma história cujo sujeito seria o povo. Mas que logo foi visto à serviço da desqualificação das sub-raças colonizadas".

$\mathrm{Na}$ aula de 4 de fevereiro de 1976, do curso Em defesa da sociedade (1975-1976), lê-se sobre os elementos que permitiram "codificar" as grandes resistências sociais nos mecanismos históricos de dominação de uma raça sobre a outra, elementos já encontrados na Idade Média.

Para Foucault (1999, p.118), "foi ainda nesse enunciado discursivo da luta racial que esses conflitos se expressaram", portanto, lê-se que as disputas da soberania contra os outros ocorreram na Inglaterra, no final do séc. XVI e início do séc. XVII e que tais discursividades surgiram "do vocabulário [engendrado pelo] fato da conquista, pela relação de dominação de uma raça sobre a outra e pela ameaça da revolta dos vencidos contra os vencedores".

Periódico Horizontes - USF - Itatiba, SP - Brasil - e019030 
A primazia da conquista e da dominação foi efetivamente formulada pela primeira vez em 1581 na obra Pro regibus apologia, produzida pelo apologista escocês Adam Blackwood que na ocasião escreveu que "deve-se compreender a situação da Inglaterra na época da invasão normanda como se compreende agora a situação da América perante as potências que não se denominavam coloniais" (BLACKWOOD, 1581 apud FOUCAULT, 1999, p.120).

Segundo Foucault (1999, p.120), Blackwood ${ }^{12}$ considerou que Carlos V, o rei da Espanha, ao subjugar as Índias Ocidentais fez na América o que os normandos fizeram na Inglaterra e, sobretudo, defendeu que "os normandos estão na Inglaterra com o mesmo direito que nós na América, ou seja, com o direito que é o da colonização".

Logo, deve-se observar que o processo de colonização transferiu padrões europeus para "as Américas", assim como teve grande influência sobre os aparelhos, mecanismos, instituições e Técnicas de Poder e Saber no Ocidente.

Foucault (1999, p.120-121) afirmou que, "temos, no final do século XVI, uma repercussão sobre as estruturas do Ocidente, da prática colonial" e, também enunciou que, "houve toda uma série de modelos coloniais que foram trazidos para o Ocidente, o que fez com que pudesse praticar em si mesmo uma colonização, um colonialismo interno".

Em síntese, com essas leituras e sem a pretensão de se esgotar essa problemática, entende-se que há uma possibilidade de análise das representações de Foucault sobre o Saber Colonial como dispositivo de regulação da população, pensado no âmbito do poder, na perspectiva dos Estudos Decoloniais.

\section{Poder/saber colonial para Foucault, Mignolo, Castro-Gómez e Grosfoguel}

Walter Mignolo (2003, p.44) escreveu que Foucault, na aula Two Lectures, 1a leitura de 7 de janeiro de 1976, introduziu em seu discurso a expressão "insurreição dos saberes subjugados" para descrever uma transformação epistemológica que ele percebia como dominante a cerca de quinze anos anteriores à sua aula.

\footnotetext{
12 Adam Blackwood (1539-1613), escritor e apologista escocês, publicou em 1575 o seu primeiro panfleto político: De Conivnctione Religionis et Imperii Libri, no qual defendeu a estabilidade religiosa como a base para a ordem política e o monarca como divinamente autorizado e o único legislador. Em 1581 escreveu Pro regibus apologia, réplica do livro Adversus Georgii Buchanani dialogum, de jure regni apud Scotos.
}

Periódico Horizontes - USF - Itatiba, SP - Brasil - e019030 
Foi duplo o significado de "saberes subjugados". Por um lado, Foucault (1980, p.81) referiu-se "aos conteúdos históricos soterrados e disfarçados numa sistematização formal", por outro lado, fez referência aos saberes subjugados, "como algo completamente diferente, ou seja, um sistema de conhecimentos inadequados à sua tarefa ou insuficientemente elaborados: conhecimentos localizados abaixo da hierarquia, do nível de cognição ou cientificidade" (FOUCAULT, 1999, p.82).

Portanto, saberes subjugados são saberes nativos, saberes populares, saberes particulares, saberes locais, embora estejam longe do conhecimento crítico. Contudo, por intermédio da reprodução desses saberes que a crítica ao Saber Colonial realiza a sua função.

Foucault (1980, p.83) notou a diferença entre os tipos de saberes com que se deparava: "saber disciplinar e acadêmico", de um lado, e "saber popular e não acadêmico", do outro, e utilizou essa diferença entre saberes para investigar seu próprio fundamento, pois, sem essa interpelação a ideia de "saberes disciplinares e saberes subjugados" não teria sentido e denominou Genealogia a união entre "saber erudito" e "memória local".

Por sua vez, Mignolo entrou em debate com Castro-Gómez e argumentou que o propósito de constituir uma análise sobre a posição colonial latino-americana levou-o a defender a tese de que houve uma tradição epistemológica na América Latina, na qual se pode pensar na colonialidade dos saberes subjugados.

Mignolo (2003, p.45) defendeu que "a distinção entre os saberes disciplinares e os saberes subjugados, permitiu que Foucault discorresse sobre o lado colonial da Modernidade".

Castro-Gómez (1996, p.150) apresentou em sua obra Crítica de la razón latinoamericana a noção de que "é precisamente no processo de relocalização da cultura que Mignolo reconhece o aporte fundamental da filosofia latino-americana".

Castro-Gómez demonstrou o valor das abordagens de Foucault para uma investigação da Colonialidade em obras como: La Hybris del Punto Cero: ciencia, raza e ilustración en la Nueva Granada (1750-1816) ${ }^{13}$, Tejidos Oníricos: movilidad, capitalismo y biopolítica en Bogotá (1910$1930)^{14}$ e, sobretudo, Michel Foucault y la colonialidad del poder (2007).

\footnotetext{
${ }^{13}$ CASTRO-GÓMEZ, S. La hybris del punto cero: ciencia, raza e ilustración em la Nueva Granada (1750-1816). Bogotá: Pontificia Universidad Javeriana, 2005.

14 CASTRO-GÓMEZ, S. Tejidos oníricos: movilidad, capitalismo y biopolítica em Bogotá (1910-1930). Bogotá: Pontificia Universidad Javeriana, 2009.
} 
Em resumo, a análise feita a respeito do Saber Colonial, no âmbito do Poder/Saber, fundamentou-se nas considerações que Mignolo e Castro-Gómez apresentaram sobre as análises de Foucault e, também, sobre o que Foucault descreveu como desenvolvimento histórico do eurocentrismo, do colonialismo e do Saber Colonial desde suas primeiras formulações até a sua introdução nas Teorias Críticas Latino-Americanas.

Foucault, na aula de 22 de março de 1978, do curso Segurança, território, população, apresentou a seguinte defesa:

A Europa, sem unidade, mas com desnível entre pequenos e grandes, tendo com o resto do mundo uma relação de utilização, de colonização, de dominação, foi esse pensamento que se formou no fim do século XVI e início do século XVII, um pensamento que vai se cristalizar no século XVIII. É isso o que é a Europa (FOUCAULT, 2008, p.400).

Portanto, a complexa história das Teorias Pós-Coloniais e Decoloniais não tardou para emergir na América Latina com apropriações dos conceitos centrais destes postulados para um estudo sócio-histórico-cultural minucioso, sobretudo, a Colonialidade inscreveu-se ao surgirem abordagens como a do Saber Colonial, com relações epistemológicas entre Europa e Américas.

Outra contribuição para uma visão foucaultiana do Saber Colonial é a de Ramón Grosfoguel em relevantes críticas na sua obra La Descolonización de la Economía Política y los Estudios Postcoloniales: transmodernidad, pensamiento fronterizo y colonialidad global.

Para Grosfoguel (2006, p.23), “existe uma série de hierarquias que configuram a cartografia do poder, entre as quais caberia sublinhar o papel crucial da hierarquia étnico-racial que privilegia aos europeus frente aos não-europeus".

Assim, trata-se de uma hierarquia entre outras, sendo que este princípio de Colonialidade, de longa duração histórica, interliga-se com as hierarquias linguísticas, epistemológicas e pedagógicas.

Segundo Grosfoguel (2006, p.28), a "colonialidade" possui dupla conotação:

De um lado, revela a continuidade das formas coloniais de dominação após o fim das tutelas produzidas pelas culturas coloniais e estruturas do mundo moderno/colonial, do outro, contém a capacidade explicativa que atualiza processos supostamente apagados ou superados pela Modernidade.

Periódico Horizontes - USF - Itatiba, SP - Brasil - e019030 
Esta perspectiva representa o principal aporte de Grosfoguel para a formulação da "Teoria Decolonial", uma vez que descarta as interpretações da Colonialidade.

Porém, Grosfoguel pareceu esquecer que Castro-Gómez utilizou, em sua tese sobre a Heterarquia, o conceito de Colonialidade do Poder, a partir de uma perspectiva foucaultiana.

Segundo Grosfoguel (2006, p.19), “a epistemologia imperial seguia situada no Norte, enquanto os objetos de estudo estariam situados no Sul".

Para Grosfoguel, os teóricos latino-americanos, ao privilegiarem os pensadores ocidentais, traíram seu objetivo de produzir estudos na perspectiva da "subalternidade" e críticou os "latinos americanistas" por privilegiarem a epistemologia de quatro pensadores: Michel Foucault, Jacques Derrida, Antonio Gramsci e Rinajit Guha:

Dos quatro pensadores que privilegiaram, três são eurocêntricos enquanto dois (Derrida e Foucault) fazem parte do canon ocidental pós-moderno. Somente um, Guha, é um pensador que produz sua reflexão desde o Sul. Ao privilegiarem pensadores ocidentais, traíram sua meta de produzir estudos subalternos (GROSFOGUEL, 2006, p.19).

Entretanto, as investigações de Castro-Gómez consistiram em avançar para uma análise aprofundada do pensamento de que permitiu avanços teóricos em relação ao Saber Colonial, sobretudo nas relações entre colonilaidade do poder, saber e ser na perspectiva das Teorias Críticas Latino-Americanas.

\section{Considerações finais}

Neste artigo procurou-se descrever posições do Grupo Modernidade/Pós-Modernidade sobre as Teorias Latino-Americanas, com referências de Aníbal Quijano, Catherine Walsh, Enrique Dussel, Ramón Grosfoguel, Santiago Castro-Gómez e Walter Mignolo, entre outros, que fizeram menções às adequações dos discursos modernos e pós-modernos acerca das práticas sócio-histórico-culturais.

Uma ênfase foi na maneira em que Foucault desenvolveu o enunciado "Saber Colonial", no âmbito do poder/saber, com o intuito de estabelerem-se aproximações e relações com as Teorias Críticas Latino-Americanas. 
Buscou-se delimitar as relações históricas do Saber Colonial e de suas apropriações nas epistemologias latino-americanas, sob a perspectiva dos Estudos Decoloniais e da forma como se empregou a Colonialidade do Saber no pensar crítico da América Latina.

Utilizou-se citações das aulas de Michel Foucault nos cursos Em defesa da sociedade e Segurança, território, população, a partir de considerações de Aníbal Quijano, Walter Mignolo, Ramón Grosfoguel, Santiago Castro-Gómez, sobre os pensamentos de Foucault.

Por fim, permitiu-se perceber que um exame mais acurado dessas questões de modo algum esgotaria as temáticas que surgissem de um debate com Foucault sobre a Colonialidade do Saber na perspectiva das Teorias Críticas Latino-Americanas.

\section{Referências}

CASTRO, E. Vocabulário de Foucault: um percurso pelos seus temas, conceitos e autores. Trad. Ingrid M. Xavier. Belo Horizonte: Autêntica, 2009.

CASTRO-GÓMEZ, S. Crítica de la razón latinoamericana. Barcelona: Puvill, 1996.

CASTRO-GÓMEZ, S. Michel Foucault y la colonialidad del poder. Revista Tabula Rasa, n.6, p.153-172, jan.-jun. 2007.

CASTRO-GÓMEZ, S. Descolonizar la universidad: la hybris del punto cero y el diálogo de saberes. In: CASTRO-GÓMEZ, S.; GROSFOGUEL, R. (Orgs.). El giro decolonial: reflexiones para una diversidad epistémica más allá del capitalismo global. Bogotá: Siglo del Hombre Editores, Instituto Pensar, 2007, p.79-91.

CASTRO-GÓMEZ, S.; GROSFOGUEL, R. Prólogo: giro decolonial, teoría crítica y pensamiento heterárquico. In: CASTRO-GÓMEZ, S.; GROSFOGUEL, R. (Orgs.). El giro decolonial: reflexiones para una diversidad epistémica más allá del capitalismo global. Bogotá: Siglo del Hombre Editores, Instituto Pensar, 2007, p.9-23.

DUSSEL, E. Filosofla de la cultura y la liberación: obras selectas II. 1. ed., Buenos Aires: Docencia, 2012.

FOUCAULT, M. Em defesa da sociedade: curso no Collège de France (1975-1976). Trad. Maria E. Galvão. São Paulo: Martins Fontes, 1999.

FOUCAULT, M. Segurança, território, população: curso no Collège de France (1977-1978). Trad. Eduardo Brandão. São Paulo: Martins Fontes, 2008. 
FOUCAULT, M. Two Lectures. In: Power/Knowledge: selected interviews and other writings 1972-1977 by Michel Foucault. New York: Pantheon Books, 1980, p.78-108.

GROSFOGUEL, R. La descolonización de la economía política y los estudios postcoloniales: transmodernidad, pensamiento fronterizo y colonialidad global. Revista Tabula Rasa, n.4, p.1748, jan-jun. 2006.

MIGNOLO, W. Histórias locais / projetos globais: colonialidade, saberes subalternos e pensamento liminar. Trad. Solange R. Oliveira. Belo Horizonte: UFMG, 2003.

QUIJANO, A. Colonialidade do poder, eurocentrismo e América Latina. In: LANDER, E. (Org.). A colonialidade do saber: eurocentrismo e ciências sociais, perspectivas latino-americanas. São Paulo: CLACSO, 2005, p.107-130.

QUIJANO, A.; WALLERSTEIN, I. Elementos del desarrollo: la americanidad como concepto, o América en el moderno sistema mundial. Revista Internacional de Ciencias Sociales: América 1492-1992, n.134, p.583-591, dez. 1992.

SILVEIRA, C. R.; AGOSTINI, N. A bíos no discurso do logos: pessoa/participante hígida em projetos de pesquisa em saúde no Brasil. Revista Conjectura: Filos. Educ., Caxias do Sul, v.22, n.3, p.536-560, set./dez. 2017.

ZEA, L. América Latina en sus ideas. México: UNESCO, Siglo XXI, 1986.

Recebido em janeiro de 2019.

Aprovado em abril de 2019. 